\title{
Evaluation of Sudanese Phosphate Rocks by Two Rapid Methods for Determination of Total and Available Phosphorus: Comparative Study
}

\author{
ADAM.A.FARAH ${ }^{1}$, SALAH.M.NOUR ${ }^{2}$, ALASSAM H. AHMED ${ }^{3}$ and H. BAYAHIA ${ }^{3}$ \\ 1'Department of Chemistry, Faculty of Education, University of Kordofan, Sudan. \\ ${ }^{2}$ ARC, Department of Plant Nutrition, Wad Madani, Sudan. \\ ${ }^{3}$ Department of Chemistry, Faculty of Science, Albaha University, Albaha, Kingdom of Saudi Arabia. \\ ${ }^{*}$ Corresponding author E-mail: adam1974999@ gmail.com \\ http://dx.doi.org/10.13005/ojc/320520
}

(Received: August 05, 2016; Accepted: October 09, 2016)

\begin{abstract}
The present work was carried out to study effectiveness of phosphate rocks discomposing by using two rapid digestion methods (single and mixed acids). A rapid method for determining $\mathrm{P}_{2} \mathrm{O}_{5}$ of phosphate rocks based on colorimetry has been determined. The loss on ignition (L.O.I) method's values is ranging between $8.80 \%$ to $25.25 \%$ for Jebel Kurun and between $13.84 \%$ to $18.78 \%$ for Uro. The comparison between determination total and available phosphorus with single digestion $\left(\mathrm{HClO}_{4}\right)$ and "mixed acids" $\left(\mathrm{HCl}, \mathrm{HNO}_{3}\right.$, and $\left.\mathrm{HClO}_{4}\right)$ showed that the total phosphorus measured by single digestion ranged between $31.51 \%$ and $44.62 \%$ of Krurn and between $27.60 \%$ and $28.52 \%$ of Uro areas. By the mixed acids method it was found to range from 19.32 , to $48.30 \% \mathrm{P}_{2} \mathrm{O}_{5}$ and $21.85 \%$ to $33.20 \%$ of Kurun and Uro respectively. The available $\mathrm{P}_{2} \mathrm{O}_{5}$ was ranged between 14.3 to $23.90 \% \mathrm{P}_{2} \mathrm{O}_{5}$ of Nuba Mountaians Jebel Kurun and between $11.10 \%$ to $18.60 \%$ for Uro area. . A comparison of methods used for colorimetric determination of total $\mathrm{P}_{2} \mathrm{O}_{5}$ indicated that the results by mixed digestion method is the highest. The production its make appear to have very promising practical application.
\end{abstract}

Keywords: phosphate rocks, mixed digestion method, total phosphorus.

\section{INTRODUCTION}

Phosphate rock is a general term used for rocks that contain a high concentration of phosphate minerals, which commonly belong to the apatite group. Phosphate rock minerals are the significant global Resources of phosphorus. Phosphorus is one of the major nutrients limiting plant growth, it's the second most important plant nutrient after nitrogen. ${ }^{1,2}$ Phosphorus from rock phosphate is used in the production of phosphate fertilizers. ${ }^{3}$ Fertilization is as necessary for the improvement of the Soil as nutrient substrate and can make a good replacement of the removed nutrients by harvesting and other processes. ${ }^{4}$ The use of the fertilizersin Sudan is often limited to irrigated agriculture and rarely practiced 
under rained areas. This may be due mainly to the financial handicaps of the farmers and unawareness about the importance of chemical fertilizers. ${ }^{5}$ In the Sudan, and because it is a big agricultural country, there is a great need to obtain cheap and safe resources of phosphate ores for phosphoric acid and phosphate fertilizer industry. ${ }^{6}$ The use of indigenous natural phosphate rocks had been recognized as available low-cost alternative for the conventional water-soluble phosphorus fertilizers though they show large differences in their suitability for direct application and many factors influence their capacity to supply phosphorus to crops. ${ }^{7}$ Since deficiency of phosphorus is the most important chemical factor restricting plant growth, chemical phosphate fertilizers are widely used to achieve optimum yields. ${ }^{8}$ The main uses of this acid are for dissolving metals (oxides, hydroxides, carbonates, sulphides and arsenide's ores). $\mathrm{HClO}_{4}$ : about $72 \%$, when hot is an extremely powerful oxidizing agent and as such will dissolve almost all metals and convert them into ions having their highest oxidation states in solution. ${ }^{9}$ A sample solution was prepared by dissolving of rock sample in an aqueous mixture of perchloric and nitric acids; the perchloric acid digestion of PRs is effective on most phosphorus minerals such as apatites. There is variety of methodologies used for determination of different forms of phosphorus from phosphate rocks. In this study a reliable methods is needed which allows to increase the phosphorus availability, and to assess the relative importance of PRs as source of phosphorus fertilizer.

\section{Statistical analysis}

The significance of differences in contents of total and available $\mathrm{P}_{2} \mathrm{O}_{5}$ percent in different phosphate rock was determined by analysis of variance (ANOVA test).

\section{MATERIALS AND METHODS}

When we come to look at actual procedures for dissolving inorganic samples (such as PR) by using hot concentrated mineral acids, we find that rather than just using a single acid, a mixture of acids is used. On the other occasions samples are treated with a mixture of acids, and then "fumed to dryness". $\mathrm{HNO}_{3}$ oxidizines $\mathrm{HCl}$ to give various reactive oxidation products such as chlorine and nitrosyl chloride. Several acids decompose under these conditions to yield decomposing products even more reactive than the acid itself; the acids will oxidize all metals except the noble ones. The molybdophosphovanadate procedure described below was used to determine of $\mathrm{P}_{2} \mathrm{O}_{5}$ in phosphate rock. The reduced-molybdophosphate method is accepted as one of the most sensitive means of determining phosphorus. Twenty four composite surface phosphate rocks samples, collected from Jebel Kurun and Jebel Uro areas these two locations lie in the center of eastern part of the Nuba Mountains in the state of southern Kordofan (Sudan) $11^{\circ} 54^{\prime} \mathrm{N}$ and $31^{\circ} 22^{\prime} \mathrm{E}$ between Abu Giubiha and El Rashad towns. ${ }^{10}$ The samples were prepared at the Laboratory of the Geological Research Authority of Sudan (GRAS), Ministry of Minerals. The samples mixed, homogenized, _crushed in a jar crushers and powdered to a fineness (200 mesh), then dried in an electric oven at $110 \mathrm{C}$ for 2 hours, then cooled and kept in desiccators for analysis. ${ }^{11}$ Loss On Ignition, total $\mathrm{P}_{2} \mathrm{O}_{5}$ determined by two rapid digestion methods (Single acid and Mixed acids), available phosphorus determined by using Olsen Method. ${ }^{12}$ One gram of PRs sample was accurately weighted into 50 $\mathrm{mL}$ beaker, $10 \mathrm{~mL}$ of concentrated $\mathrm{HCl}, 5 \mathrm{~mL}$ of concentrated $\mathrm{HNO}_{3}$, and few anti-bombing granules, was added. The mixture was heated to evaporate off the oxides. The solution was heated till the residue was about $5 \mathrm{~mL}$. Then $5 \mathrm{~mL}$ of perchloric acid $70 \%$ added, the mixture was maintained at the boilingpoint until the fumes were driven off suddenly. Then cold to the room temperature and $50 \mathrm{~mL}$ of distilled water was added, boil for three minutes, cold again and filtered into conical flask by using Whitman No.42. A $5 \mathrm{~mL}$ of stock standard solution $0,5,10,20$, 25 and $5 \mathrm{~mL}$ of a portion of an aliquot samples, and $20 \mathrm{~mL}$ of reagent were added into $100 \mathrm{~mL}$ volumetric flask, fill with distilled water, shakes and the blank of standard potassium di-hydrogen phosphate were used to calculate total phosphorus as $\mathrm{P}_{2} \mathrm{O}_{5}$ after 20 minutes wavelength was set at $640 \mathrm{~nm}$.

2.5 grams of PRs samples were accurately weighted in $250 \mathrm{~mL}$ conical flask, $30 \mathrm{~mL}$ of concentrated $\mathrm{HClO}_{4}(70 \%)$ and few pumice stones was added, pre-heated the flask to about $100^{\circ} \mathrm{C}$, temperature was increased gradually to $180^{\circ} \mathrm{C}$ and digest the samples till dense white fumes of oxides appeared. Extra little $\mathrm{HClO}_{4}$ was used to wash down the sides of the digestion flask; the heating was 
continued boiling temperature for 20 minutes. At this stage the insoluble materials become like white sand. The total digestion with $\mathrm{HClO}_{4}$ acid usually requires about 40 minutes, ${ }^{13}$ the mixture was cooled, diluted with distilled water to the volume mark, mixed well filtrated through filter paper Whitman No.42. $10 \mathrm{~mL}$ of aliquot samples of PRs was pipetted into 100 $\mathrm{mL}$ volumetric flask, $20 \mathrm{~mL}$ of reagent was added, the absorbance of total phosphorus was measured after $20 \mathrm{~min}$. at wavelength $460 \mathrm{~nm}$ using blank and standard solutions.

\section{RESULTS AND DISCUSSION}

A calibration curves (Figures 1 and 2) was constructed and used to calculate the concentration of $\mathrm{P}_{2} \mathrm{O}_{5}$. Organic matters is an important component when determined by Loss On Ignition (L.O.I) techniques because it tends to either form soluble or insoluble materials (the heavy metals), as a result it can be migrate or retained in the soil. ${ }^{14}$ Tables (1) showed the average content of (L.O.I), the values was relatively low to moderate of all samples which suggested that these samples have a slightly lower organic materials calcite or gypsum content. The L.O.I was ranged between $8.80 \%$ to $25.25 \%$ for Jebel Kurun, and was found to be ranged between 13.84\% to $18.78 \%$ for Jebel Uro area table (2). Table. 1 shows that the total $\mathrm{P}_{2} \mathrm{O}_{5}$ determined by mixed digestion method was ranged between $19.32 \%$ to $46.00 \%$ for Jebel Kurun area, and by another digestion method have been found that between $27.60 \%$ to $44.62 \%$, from these two mentioned methods the mixed one was gave highest values of total $\mathrm{P}_{2} \mathrm{O}_{5}$

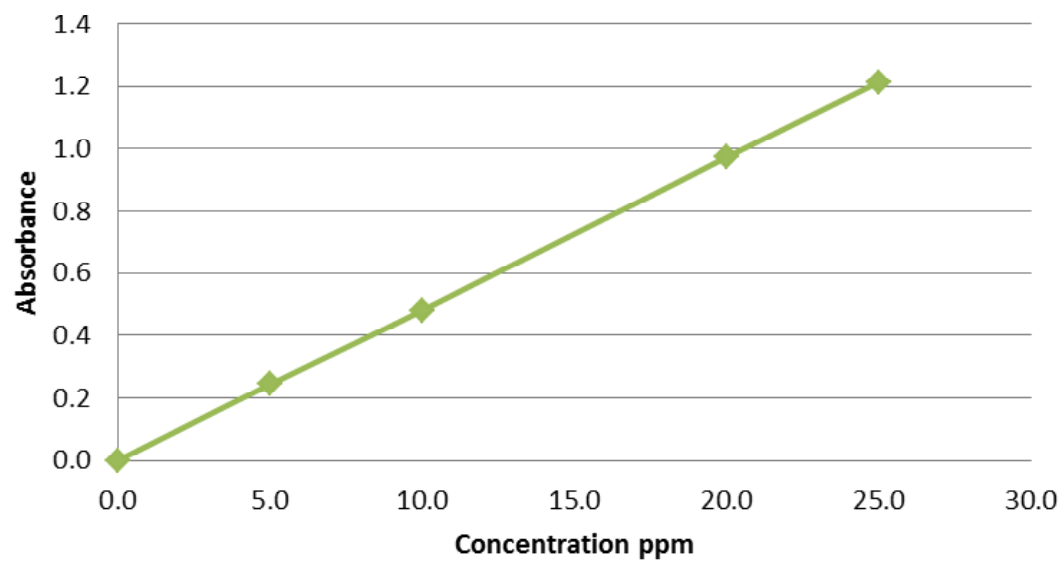

Fig. 1: A calibration curve of absorbance of standard solutions calculate the concentration of $\mathrm{P}_{2} \mathrm{O}_{5} \%$ by mixed acids

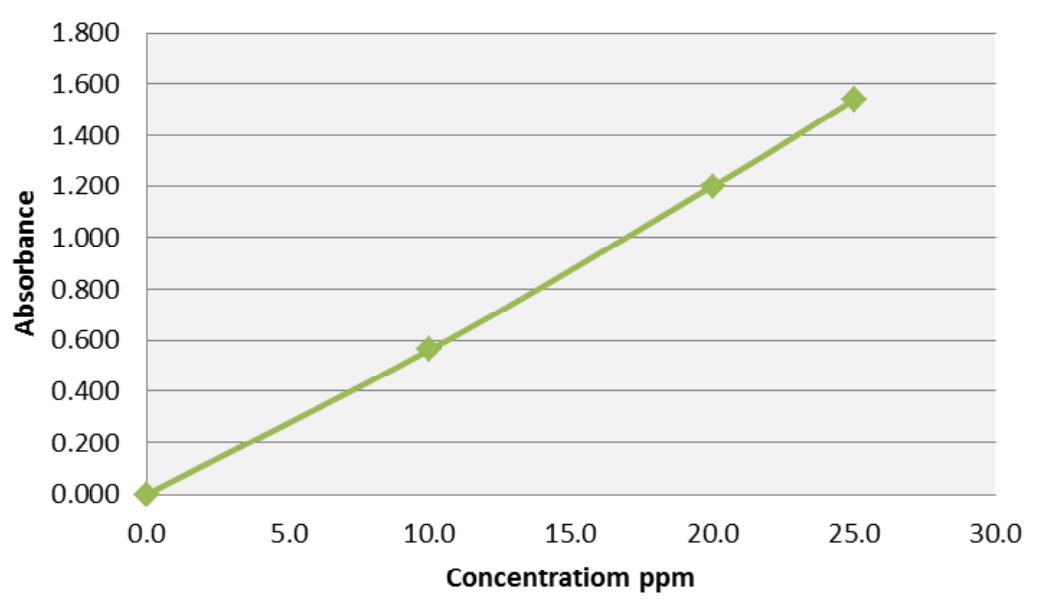

Fig. 2: A calibration curve of the absorbance of standard solutions of $\mathrm{KH}_{2} \mathrm{PO}_{4}$ calculate the concentration of $\mathrm{P}_{2} \mathrm{O}_{5}$ in the samples solutions by single acid digestion method 
Table 1: Chemical analysis of L.O.I total and available $\mathrm{P}_{2} \mathrm{O}_{5}$ using two rapid methods (single \& mixed digestion acids) of Jebel Kurun area

\begin{tabular}{lcccc}
\hline $\begin{array}{l}\text { Sample } \\
\text { No. }\end{array}$ & L.O.I\% & $\begin{array}{c}\text { Mixed } \\
\text { acids }\end{array}$ & HCIO $_{4}$ & Available \\
\hline K1 & 16.78 & 44.16 & 43.24 & 16.3 \\
K2 & 16.99 & 46 & 44.62 & 20.91 \\
K3 & 18.73 & 33.81 & 43.01 & 15.6 \\
K4 & 19.29 & 42.32 & 34.04 & 16.3 \\
K5 & 14.06 & 43.7 & 33.81 & 19.3 \\
K6 & 10.22 & 46 & 33.12 & 20.2 \\
K7 & 12.91 & 43.97 & 35.65 & 23 \\
K8 & 19.39 & 43.97 & 36.34 & 14.3 \\
K9 & 17.83 & 42.59 & 36.8 & 22.5 \\
K10 & 25.25 & 48.3 & 34.73 & 21.2 \\
K11 & 16.3 & 33.35 & 35.65 & 23.9 \\
K12 & 19.41 & 40.02 & 34.27 & 22.5 \\
K13 & 9.48 & 38.18 & 35.19 & 20.9 \\
K14 & 18.67 & 34.96 & 34.04 & 23 \\
K15 & 14.74 & 34.5 & 35.88 & 22.5 \\
K16 & 9.14 & 33.59 & 34.5 & 16.3 \\
K17 & 8.94 & 23.46 & 27.6 & 15.9 \\
K18 & 10.41 & 33.35 & 36.57 & 20.5 \\
K19 & 8.84 & 29.44 & 34.96 & 23.9 \\
K20 & 8.8 & 19.32 & 33.12 & 21.2 \\
Mean & 15.52 & 37.53 & 35.86 & 20.01 \\
Median & 18.69 & 39.1 & 35.08 & 20.9 \\
CV\% & 6.89 & 20.76 & 10.79 & 15.49 \\
Std. Dev & 1.07 & 7.79 & 3.87 & 3.1 \\
SE Mean & 2.53 & 1.74 & 0.87 & 0.69 \\
\hline & & & & \\
\hline
\end{tabular}

content than the single method, indication to the highest apatite content. However, Table (2) shows the total phosphorus for Jebel Uro area was found to be ranged between $21.82 \%$ to $33.20 \%$ by mixed method, but by another digestion method ranged between $28.52 \%$ to $31.15 \%$ of total phosphorus. However, total phosphorus content is not indication of phosphate rock, agronomic effectiveness, till the available phosphorus was determined. ${ }^{15}$ The available $\mathrm{P}_{2} \mathrm{O}_{5}$ of Jebel Kurun was found to be ranged between $19.90 \%$ to $23.90 \%$, this result indicated to enrich of these phosphate rocks ores with phosphate minerals such as: Hydroxyl-Fluor-apatite, $\mathrm{Ca}_{10}\left(\mathrm{PO}_{4}\right)_{6} \mathrm{~F}_{2}$, Carbonate-apatite $\mathrm{Ca}_{10}\left(\mathrm{PO}_{4}, \mathrm{CO}_{3}\right)_{6}(\mathrm{OH}, \mathrm{F})$, Hydroxyl apatite $\mathrm{Ca}_{10}\left(\mathrm{PO}_{4}\right)_{6}(\mathrm{OH})_{2}$, Chlor-apatite $\mathrm{Ca}_{10}\left(\mathrm{PO}_{4}\right)_{6} \mathrm{Cl}_{2}$. Based on data which obtained from the analyzed
Table 2: A chemical analysis of L.O.I total and available $\mathrm{P2O5}$, using two rapid methods (single and mixed digestion acids) of Jebel Uro

\begin{tabular}{lcccc}
\hline $\begin{array}{l}\text { Sample } \\
\text { No. }\end{array}$ & L.O.I & $\begin{array}{c}\text { Mixed } \\
\text { acids }\end{array}$ & $\mathrm{HCIO}_{4}$ & Available \\
\hline U1 & 18.78 & 21.85 & 28.52 & 18.6 \\
U2 & 13.84 & 31.85 & 29.44 & 16.1 \\
U3 & 14 & 23.46 & 30.13 & 11 \\
U4 & 14.59 & 33.2 & 31.51 & 16.7 \\
Mean & 32.8 & 29.12 & 29.21 & 15.85 \\
Median & 17.18 & 31.22 & 29.9 & 16.4 \\
CV\% & 9.76 & 16.83 & 4.31 & 20.89 \\
Std. Dev & 3.2 & 4.9 & 1.26 & 3.2 \\
SE Mean & 1.6 & 2.45 & 0.63 & 1.6 \\
\hline
\end{tabular}

total and available phosphorus contents of PRs with digestion technique by using mixed acids $\left(\mathrm{HNO}_{3}\right.$, $\mathrm{HCl}$ and $\left.\mathrm{H}_{2} \mathrm{SO}_{4}\right)$ and single acid $\left(\mathrm{HClO}_{4}\right)$, extraction procedure it can be concluded that the digestion with mixed acids technique can be useful in determination of total phosphorus. Table ( $1 \& 2$ ) comparing the results of two extraction methods mixed and single acid showed highest value of both total and available phosphorus of Phosphate Rocks for the mixed acid digestion due to the strength of mixed acids than single acid. In comparing between two distinct areas for value of available phosphorus from Sudanese phosphate rock, found that Jebel Kurun area ranged between $14.30 \%$ to $23.90 \%$, and between $11.10 \%$ to A comparison of two methods used for determination of dissolved total phosphorus of phosphate rocks was showed in table (1). The methods compared different approaches to oxidizing organic phosphorus compounds, and destroying polyphosphates to give forms total and available to standard colorimetric methods. The mixed acids $\left(\mathrm{HCl}, \mathrm{HNO}_{3}\right.$ and $\left.\mathrm{HClO}_{4}\right)$ reflux fuming was a techniques to evaporated $\mathrm{PRs}$ samples with this strong acids in covered beaker it gave a highest total $P$ content of Jebel Kurun deposits phosphate and the lowest in Uro. The methods are rapid and have proved very useful in quickly evaluating the phosphate rock potentialities of an area economically.

\section{CONCLUSION}

Based on the results obtained from this study on compression between two digestion methods 
determination of phosphorus from phosphate rock can be draw attention to the following salient points as concluding remarks. Raw phosphate rocks represent an alternative for currently used phosphate fertilizers due to costs and energy limitations. To prove suitability and adequacy of phosphate rock of Nuba Mountains (Jebel Kurun) and other parts of Sudan for fertilizers industry further detailed investigations are required.

\section{REFERENCES}

1. Donahue. R.L., Miller, R.W \& Shickluna, J.C. 1990, 110001, 2-4.

2. Hamadali. H. Moursalou, K. Tchangbedji, G., Ouhdouch, Y. and Hafidi, M., African. Journal of Biotechnology, 2012, 11, 312-320.

3. FAO. 2006, Use of phosphate rock for sustainable agriculture, FAO Fertilizer and plant nutrition Bulletin No. 13. Rome.

4. Mohamed. S.A., Ph. D thesis, Faculty of Agriculture, University of Khartoum, Sudan, 2002.

5. Adam. A.A., \& EL-tayeb, M.H., Argentine. Chemistry Society,2010, 97, 166-177.

6. Kaleeswari. R.K \& Subramanian, S., Agriculture Research-J., 1972 2, 121-126.

7. Zapata. F., Final report on the FAO/IAEA, 1999, DI -50-03 Vienna, Austria.
8. Chien. S.H., Menon, R.G. \& Billingham, K.S., Soil Sci. Soc. Am. J., 1996, 60, 1173-1177.

9. Richard. A., Sample Pretreatment and Separation, Analytical chemistry ACOL ,series New York. 1987.

10. Whiteman. A. J., The Geology of the Sudan Republic. Clarendon Press, Oxford, Unite Kingdom. 1971

11. Mullins. G.L.; Evans. C.E., Fertilizer Research J., 1990, 25, 101-106..

12. Olsen. S. R., and Sommer, L.E., 1982, 403430.

13. Sommers. I.E., and Nelson. D.W., soil. Soci, Amer, proc , 1972, 36, 902-904.

14. Abimbola. A.F., Ojo. A.M. Okunlola, and Oguntoyinbo, F.I., Nigeria Journal of Science, 2002, 36, 119-128.

15. Ward. F. N., Lakin, F.C., Canney., Geological survey Bulletin, 1963, 1152. 